\title{
Life Sciences
}

ELSEVIER

Life Sciences 67 (2000) 1455-1465

\section{Interaction of the human DnaJ homologue, HSJ1b with the $90 \mathrm{kDa}$ heat shock protein, Hsp90}

\author{
Tamás Schnaider ${ }^{\mathrm{a}}$, Csaba Sőtia ${ }^{\mathrm{a}}$ Michael E. Cheetham ${ }^{\mathrm{b}}$, Yoshihiko Miyata ${ }^{\mathrm{c}}$, \\ Ichiro Yahara ${ }^{\mathrm{d}}$, Péter Csermely ${ }^{\mathrm{a}, *}$ \\ ${ }^{a}$ Department of Medical Chemistry, Semmelweis University, P.O. Box 260, H-1444 Budapest 8, Hungary \\ ${ }^{b}$ Department of Pathology, Institute of Ophthalmology, University College of London, London, UK \\ ${ }^{\mathrm{c}}$ Department of Cell and Developmental Biology, Kyoto University, Kyoto, Japan \\ ${ }^{\mathrm{d}}$ Department of Cell Biology, the Tokyo Metropolitan Institute of Medical Science and CREST, \\ Japan Science and Technology Corporation, Tokyo, Japan
}

\begin{abstract}
The $90 \mathrm{kDa}$ heat shock protein (Hsp90) is a major cytoplasmic molecular chaperone associating with numerous other proteins. Both genetic and in vitro refolding experiments using reticulocyte lysate have suggested a functional interaction of Hsp90 with yeast human homologues of E. coli DnaJ. Here we present direct evidence using surface plasmon resonance that Hsp90 and the human DnaJ homologue, HSJ1b, bind to each other. We also show that Hsp90 and HSJ1b transfer $\alpha$-lactalbumin to each other in an ATP-dependent manner. The two chaperones have additive effects in preventing rhodanese aggregation. (C) 2000 Elsevier Science Inc. All rights reserved.
\end{abstract}

Keywords: Molecular chaperone; Hsp90; DnaJ; HSJ1b; Surface plasmon resonance; Rhodanese

\section{Introduction}

The $90 \mathrm{kDa}$ heat shock protein (Hsp90) is a major cytoplasmic molecular chaperone, which binds to early intermediates of protein folding, is able to keep the target protein in a folding-competent state and can be inhibited by divalent cations (1-6). DnaJ (the E. coli homologue of eukaryotic Hsp40) and its eukaryotic homologues bind to and regulate members of the DnaK/Hsp70 family (7-9). These DnaJ-like proteins are important regulators of protein folding, transport, translation initiation, gene expression and growth control. In contrast to Hsp70, that prefers target proteins with an extended conformation, the DnaJ-like proteins bind to partially folded proteins exhibiting a significant amount of secondary and tertiary

\footnotetext{
* Corresponding author. Fax: +361-266-6550.

E-mail address: csermely@puskin.sote.hu, http://www.chaperone.sote.hu/ (P. Csermely)
} 
structure. Hsp90 is able to form complexes with a variety of other proteins including other molecular chaperones, such as Hsp70, and several other members of the "foldosome" required for the correct assembly of steroid receptors (1-3).

Genetic studies of Kimura et al. (10) and Caplan et al. (11) indicated that Hsp90 functionally interacts with the yeast homologue of DnaJ, YDJ1 in the maturation of several Hsp90 substrates such as the Src tyrosine kinase or the glucocorticoid receptor. Other reports demonstrated that Hsp70, Hsp90 and both protein YDJ-1 and the rabbit homologue, Hsp40, cooperate in refolding of thermally denatured firefly luciferase as well as in the in vitro maturation process of the glucocorticoid receptor $(11,12)$. Our results indicate, that Hsp90 and the human DnaJ-homologue, HSJ1b, both physically and functionally interact. The two chaperones bind partially denatured $\alpha$-lactalbumin in an ATP-dependent manner, and have additive effects in preventing rhodanese aggregation.

\section{Materials and methods}

\section{Chemicals}

Chemicals for the coupling of proteins to the surface plasmon resonance sensor chips were purchased from Pharmacia Biosensor AB (Uppsala, Sweden). Hydroxyapatite was an EconoPac HTP column from BioRad (Richmond, CA). Chromatography media were purchased from Pharmacia LKB Biotechnology Inc. (Uppsala, Sweden). Recombinant human Hsp27 (SPP715), bovine Hsc70 (SPP-750), and the AC-88 monoclonal anti-Hsp90 antibody were from StressGen (Victoria, BC, Canada). Polyclonal anti-Hsp90 antibody was prepared as described earlier (14). All the other chemicals used were from Sigma Chemicals Co. (St. Louis, MO).

\section{Hsp90 and HSJIb}

Hsp90 was isolated from livers of 4 months old, male Sprague-Dawley rats, from human placentas, or from the L5178Y mouse cell line as described earlier (15). Experiments were usually performed with rat Hsp90. When repeated with Hsp90 from a different source, no significant differences were observed in the results with the notable exception of the ATPase measurements, where human Hsp90 displayed higher activities than rat or mouse Hsp90. Recombinant HSJ1b has been expressed in E. coli, and purified by subsequent chromatographies on DEAE-Sepharose CL-6B and hydroxylapatite columns as described earlier $(16,17)$. The purity of the preparations was higher than $95 \%$ (usually higher than 98\%) as judged by densitometry of silver stained SDS slab gels. Protein concentrations were determined using the Bradford method (18).

\section{Surface plasmon resonance (SPR) measurements}

SPR measurements have been performed as described earlier $(19,20)$. Briefly: rat Hsp90 (protein concentration: $30 \mu \mathrm{g} / \mathrm{ml}$ ) or HSJ1b (protein concentration: $25 \mu \mathrm{g} / \mathrm{ml}$ ) was coupled to the chip in a buffer containing $10 \mathrm{mM} \mathrm{Na}$-formate, $\mathrm{pH} 4.0$, for 7 minutes at $25^{\circ} \mathrm{C}$ at a flow rate of $5 \mu \mathrm{l} / \mathrm{min}$. The remaining active sites of the resin were inactivated by incubation with a 
$1 \mathrm{M}$ ethanolamine. $\mathrm{HCl}$ solution. After coupling non-covalently bound proteins were removed by 2 or 3 brief ( 2 minutes) fluxes of $20 \mathrm{mM} \mathrm{HCl}$. The usual change in the angle of the SPR minimum of the reflected light after coupling of Hsp90 was approximately 0.9 degrees, i.e.

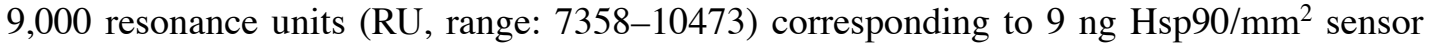
chip (19). The respective values for HSJ1b were: 0.6 degrees, 6,000 RU (range: 5400-6500) $6 \mathrm{ng} \mathrm{HSJ} 1 \mathrm{~b} / \mathrm{mm}^{2}$ sensor chip. Binding of various proteins was analyzed in a running buffer containing $10 \mathrm{mM}$ Hepes, $\mathrm{pH} 7.4,0.15 \mathrm{M} \mathrm{KCl}$ and $0.001 \%$ Tween-20. After a binding experiment had been completed, occasionally a brief ( 2 minutes) wash with $20 \mathrm{mM} \mathrm{HCl}$ was applied to remove the proteins, non-covalently adsorbed to the chip. With this procedure the baseline was remarkably stable ( $\pm 3 \%$ ) even after repeated binding experiments up to 50 times. Repeating the experiments in a different order did not result in significant differences of the binding curves, which shows that the baseline stability is a good criteria for the resorption of bound proteins, and also reflects that the occasional brief $\mathrm{HCl}$-washes did not denature the immobilized proteins significantly. With one coupling all measurements were made within 8 hours and the same sensor was used for maximum 3 days after opening. All the binding experiments were repeated with "mock-coupled" sensor chips, where in the coupling procedure no proteins were applied. Binding curves (sensorgrams) were corrected by subtracting the electrostatic binding of proteins and the occasional changes in the refractive index of the buffer. Special care was taken to reduce the latter phenomenon to the possible minimum throughout the experiments. Repeating some of the experiments with certified sensor chips did not show any significant difference. The portion of the sensorgrams which corresponds to the dissociation of various proteins from the immobilized chaperone was analyzed by the BIA evaluation program 3.0 to obtain $\mathrm{k}_{\mathrm{d}}$. The content of the dissociation buffer has been modified by the various additions of the particular experiment. The experimental data fit well to the single exponential kinetic model used. Some experiments have been repeated at a flow rate of $10 \mu \mathrm{l} / \mathrm{min}$ to check the effect of possible rebinding. Rebinding and mass transfer limitation was also checked by the repetition of the experiments at lower levels of immobilized Hsp90. The identical results showed that these phenomena did not occur under the conditions used. Using the corresponding $\mathrm{k}_{\mathrm{d}}$ values, nonlinear curve fitting to the association phase of the corresponding sensorgram was carried out with the BIA evaluation program 3.0 to obtain $\mathrm{k}_{\mathrm{a}} \cdot \mathrm{K}_{\mathrm{d}}$ was calculated as $\mathrm{k}_{\mathrm{d}} / \mathrm{k}_{\mathrm{a}}$.

\section{Autophosphorylation of Hsp90 and measurement of Hsp90-associated ATP-ase activity}

Measurement of the Ca-ATP-dependent autophosphorylation and associated ATP-ase activity of highly purified Hsp90 preparations was performed as described earlier $(15,21)$. All measurements performed were in the absence of an ATP regenerating system.

\section{Chaperone-assisted refolding of rhodanese}

The refolding assay was performed essentially as described by Langer et al. (22). Briefly, rhodanese (R 1756, Sigma; $4.6 \mu \mathrm{M}$ ) was denatured in $6 \mathrm{M}$ guanidinium. $\mathrm{HCl}, 30 \mathrm{mM}$ Hepes, $\mathrm{pH} 7.4,5 \mathrm{mM}$ DTT and diluted 100 -fold to a reaction buffer containing $30 \mathrm{mM}$ Hepes, $\mathrm{pH}$ 7.4, $50 \mathrm{mM} \mathrm{KCl}, 0.5 \mathrm{mM}$ EDTA. Aggregation of rhodanese was monitored following the $90^{\circ}$ light scattering at $320 \mathrm{~nm}$ at room temperature in a Hitachi F-4500 spectrofluorometer. 


\section{Results}

\section{Binding of Hsc70 and HSJIb to Hsp90 and to each other}

Hsp90 forms a complex with Hsc70 and several homologues of the E. coli DnaJ protein $(1-3,11,12)$. To test the binding affinity of purified Hsc70 and one of the human DnaJ homologues, HSJ1b to Hsp90 we immobilized Hsp90 on a sensor chip of a BIACore surface plasmon resonance (SPR) instrument and analyzed the complex formation of Hsc70 and HSJ1b with immobilized Hsp90. Fig. 1 indicates that indeed, both Hsc70 and HSJ1b bound to Hsp90. The dissociation constant of Hsc70/Hsp90 complex was $700 \pm 70 \mathrm{nM}$, while the HSJ1b/Hsp90 complex displayed an approximately fourfold higher binding affinity (200 \pm $30 \mathrm{nM}$ ). The Hsp27/Hsp90 complex showed the least stability compared with Hsc70 and HSJ1b in our system $(900 \pm 100 \mathrm{nM}$ ). Binding of recombinant human Hsp70 (SPP-755 of StressGen) to Hsp90 was similar to that of Hsc70 (data not shown). In agreement with previous results $(16,17)$, Hsc70 bound tightly to its co-chaperone, to immobilized HSJ1b $(200 \pm 20 \mathrm{nM}$, data not shown), which is similar to the affinity of DnaK/DnaJ interactions (544 nM, ref. 22).

\section{Binding of $\alpha$-lactalbumin to Hsp90 and to HSJ1b}

In agreement with earlier results indicating that Hsp90 binds to early folding intermediates (4), $\alpha$-lactalbumin did not bind to immobilized Hsp90 (Fig. 2). On the contrary, both $\mathrm{S}$-carboxymethylated $\alpha$-lactalbumin (CM-lactalbumin, a completely denatured form of lactalbumin; 23) and guanidinium.HCl-treated then partially renatured $\alpha$-lactalbumin (calciumdepleted apo-lactalbumin) showed a significant binding to Hsp90. Due to the long capillaries of the BIACore apparatus, binding of apo-lactalbumin started after $80 \mathrm{sec}$ of the 100-fold dilution of guanidinium.HCl-denatured lactalbumin to the running buffer. During this time apo-lactalbumin could be partially renatured (24). Apo-lactalbumin had a higher affinity to Hsp90, than CM-lactalbumin (Fig. 2A). Similar binding characteristics was observed when various forms of $\alpha$-lactalbumin were allowed to bind to immobilized HSJ1b (Fig. 2B). The inability of HSJ1b to bind $\alpha$-lactalbumin together with its much reduced affinity for the completely denatured CM-lactalbumin versus the partially unfolded apo-lactalbumin is also in agreement with earlier reports for HSJ1b (17), DnaJ (23) and YDJ1 (25).

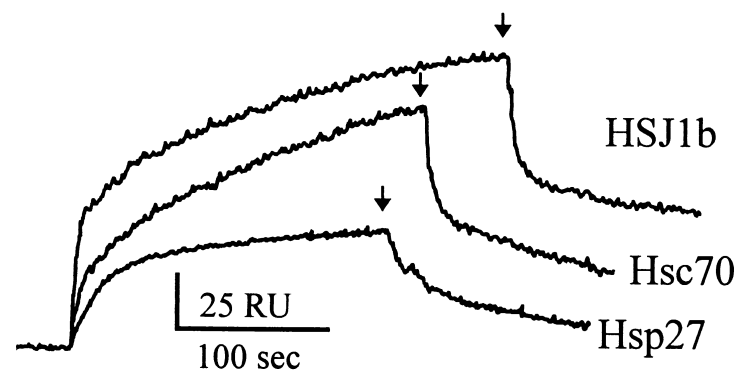

Fig. 1. Surface plasmon resonance sensorgram analyzing the interaction of Hsp27, Hsc70 and HSJ1b with Hsp90. Chaperones were added in the presence of $2 \mathrm{mM} \mathrm{Mg}^{2+}$ at a final concentration of $100 \mu \mathrm{g} / \mathrm{ml}$. At the arrows the sensor chip was washed with the running buffer to record the dissociation phase. Sensorgrams are representatives of minimum 3 experiments. 


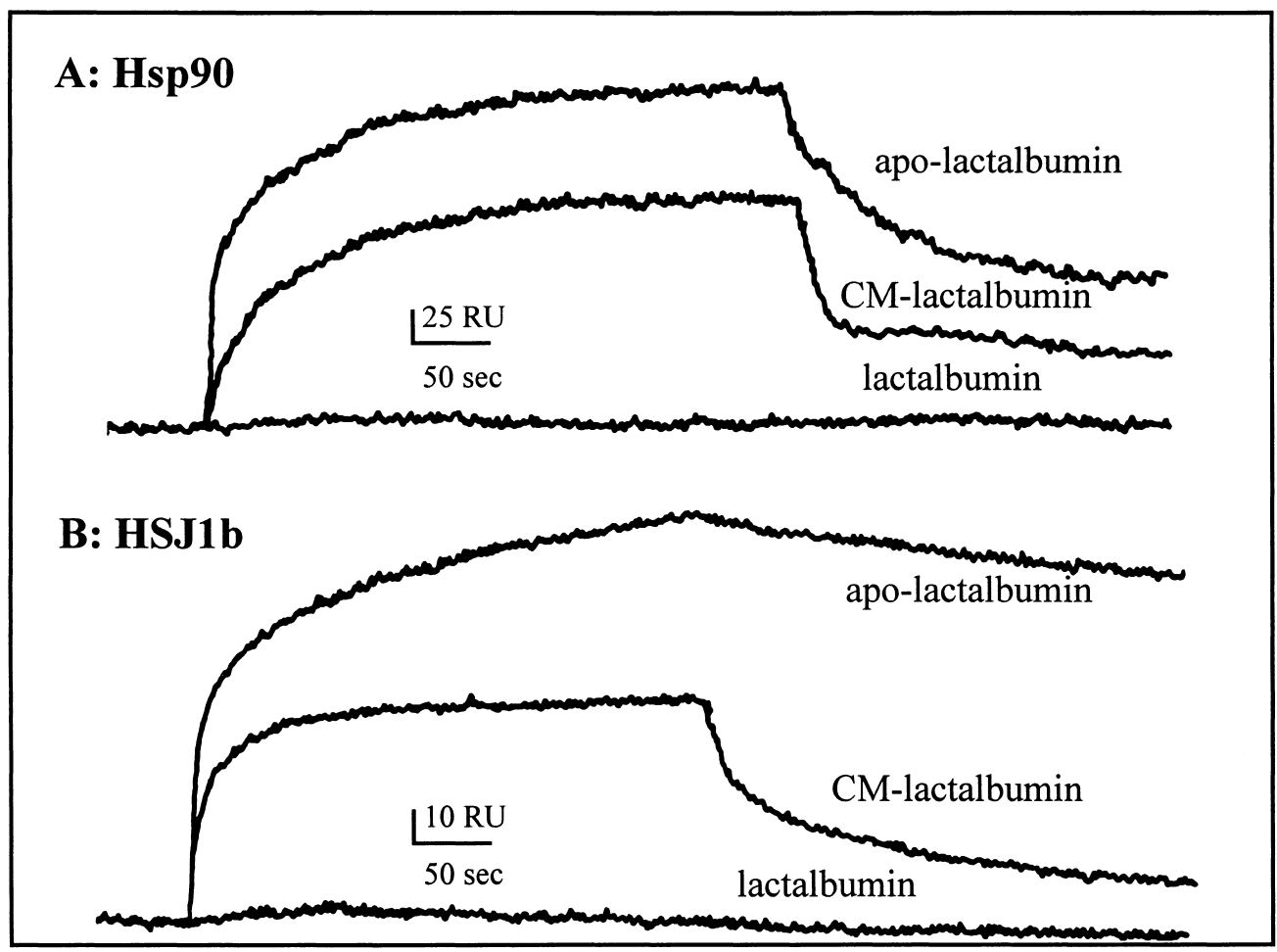

Fig. 2. Binding of various forms of $\alpha$-lactalbumin to Hsp90 and to HSJ1b. Panel A: Binding of $\alpha$-lactalbumin to Hsp90. $\alpha$-lactalbumin (Type-III, L 6010, Sigma) was added at a final concentration of $50 \mu \mathrm{g} / \mathrm{ml}$ to immobilized rat Hsp90 with, or without prior denaturation as indicated. Denaturation of lactalbumin was performed by incubation of the protein at a concentration of $5 \mathrm{mg} / \mathrm{ml}$ in $6 \mathrm{M}$ guanidinium. $\mathrm{HCl}$ for 5 minutes at room temperature. Lactalbumin was partially renatured by diluting to the running buffer of the SPR experiments (apo-lactalbumin). Binding of S-carboxymethyl $\alpha$-lactalbumin (CM-lactalbumin, $250 \mathrm{ug} / \mathrm{ml}$; L 5888, Sigma) is also shown. Panel B: Binding of native, apo- and CM-lactalbumin to HSJ1b. RU = resonance units. Sensorgrams are representatives of minimum 3 experiments.

Since apo-lactalbumin had the highest affinity for both Hsp90 and HSJ1b, we have examined the binding of this protein under various conditions in details. Fig. 3A shows the binding of apo-lactalbumin to immobilized Hsp90 in the absence or presence of magnesium or $\mathrm{Mg}$ ATP. Magnesium reduces the binding affinity of apo-lactalbumin to Hsp90 compared to the control values in agreement with earlier observations on the divalent cation-induced inactivation of the Hsp90-chaperone (5). The $\mathrm{Mg}^{2+}$-induced change is reversed, when Mg-ATP is added to the system (Fig. 3A). On the contrary, HSJ1b shows maximal binding of apo-lactalbumin in the presence of magnesium, which is reduced to the control level by the addition of Mg-ATP (Fig. 3B). The opposite changes in the dissociation constants of the Hsp90- versus HSJ1bapo-lactalbumin complexes upon the addition of ATP are from $4.4 \pm 1.2$ to $0.6 \pm 0.2 \mu \mathrm{M}$, or from $1.0 \pm 0.3$ to $2.0 \pm 0.4 \mu \mathrm{M}$ in case of Hsp90 and HSJ1b, respectively.

Observing the opposite changes in the apo-lactalbumin binding affinities of Hsp90 and HSJ1b, next we have examined if apo-lactalbumin can be transferred from Hsp90 to HSJ1b 


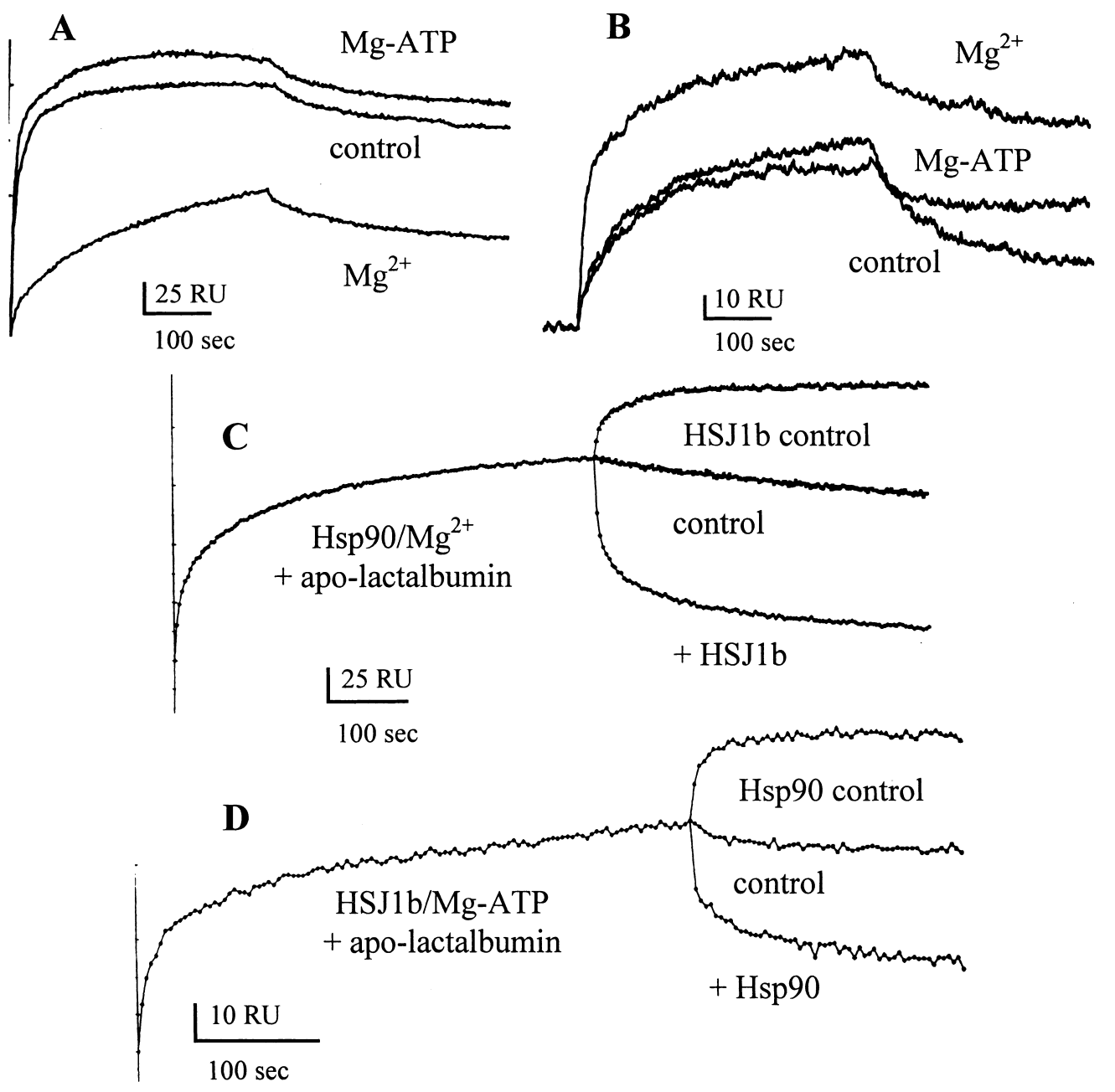

Fig. 3. Effect of ATP on binding of apo-lactalbumin to Hsp90, or to HSJ1b. Apo-lactalbumin was added to immobilized proteins after 100-fold dilution from a denaturing solution containing $5 \mathrm{mg} / \mathrm{ml}$ lactalbumin in $6 \mathrm{M}$ guanidinium. $\mathrm{HCl}$ in the presence or absence of $2 \mathrm{mM} \mathrm{MgCl}_{2}$ or $1 \mathrm{mM} \mathrm{ATP}$, as indicated. Sensorgrams are representatives of minimum 5 experiments. Panel A: Binding of apo-lactalbumin to Hsp90. Panel B: Binding of apolactalbumin to HSJ1b. Panels C and D: Competition of Hsp90 and HSJ1b $(50 \mu \mathrm{g} / \mathrm{ml})$ to bind apo-lactalbumin. $\mathrm{RU}=$ resonance unit.

in the presence of $\mathrm{Mg}^{2+}$. We also examined if apo-lactalbumin can be transferred from HSJ1b to Hsp90 in the presence of Mg-ATP. Data of Fig. 3C and D show that indeed, this is the case. If apo-lactalbumin had been allowed to bind to immobilized Hsp90 in the presence of $\mathrm{Mg}^{2+}$, apo-lactalbumin could be removed by HSJ1b (Fig. 3C, bottom curve). The dissociation phase was not corrected to the possible binding of HSJ1b (shown from a separate experiment as the top curve for comparison) which may further enhance the effect observed. Spontaneous dissociation of apo-lactalbumin (middle curve) is much smaller. If apo-lactalbumin 
had been allowed to bind to immobilized HSJ1b in the presence of Mg-ATP, it could be removed by Hsp90 (Fig. 3D, bottom curve). As before the dissociation phase was not corrected to the possible binding of Hsp90 (shown from a separate experiment as the top curve for comparison). Spontaneous dissociation of apo-lactalbumin (middle curve) is much smaller. Hsp90-mediated "transfer" of apo-lactalbumin could be blocked by both polyclonal and monoclonal (AC-88) anti-Hsp90 antibodies. Transfer also occurred, if we substituted $\mathrm{Mg}^{2+}$ with $\mathrm{Ca}^{2+}$. In the reverse experiments, apo-lactalbumin could be transferred from Hsp90lactalbumin complex to the HSJ1b-lactalbumin complex in the presence of $\mathrm{Mg}^{2+}$, but not in the presence of Mg-ATP. Vice versa, apo-lactalbumin could be transferred from HSJ1blactalbumin complex to the Hsp90-lactalbumin complex in the presence of Mg-ATP, but not in the presence of $\mathrm{Mg}^{2+}$ (data not shown).

\section{HSJ1b-induced changes in the autophosphorylation of Hsp90 and in the Hsp90-associated ATP-ase activity}

Several proteins, including F-actin and the loosely bound Hsp27 inhibit the Hsp90-associated Ca-ATP-ase activity and activate the autophosphorylation of Hsp90 (21). The interactions of Hsp90 and HSJ1b together with the ATP-induced changes in the binding affinity of Hsp90 and HSJ1b towards apo-lactalbumin prompted us to investigate if HSJ1b induces any changes in the autophosphorylation and associated ATP-ase activity of Hsp90. Our results indicate that HSJ1b has no significant effect on the human Hsp90-associated Ca-ATP-ase activity (data not shown). On the other hand, HSJ1b induces the autophosphorylation of Hsp90 to $416 \pm 6 \%$ of the control value. Identical molar amount of bovine serum albumin did not change any of the Hsp90 activities tested (data not shown).

\section{Effect of Hsp90 and HSJ1b on the refolding of denatured rhodanese}

Next we have examined if the addition of ATP changes the chaperone activity of Hsp90, HSJ1b or the combination of the two proteins. ATP induced a minor ( $p<0.02$ at 5 -fold excess of Hsp90 over rhodanese) improvement in the chaperone activity of Hsp90. The chaperone activity of HSJ1b was only marginally affected by ATP (Fig. 4A). For the examination of the additivity of the Hsp90- and HSJ1b-induced protection of rhodanese aggregation we have selected two doses of each chaperone inducing a smaller and somewhat larger protection if acting alone. In the presence of magnesium an additive effect of the two chaperones has been observed when 5-fold molar excess of Hsp90 was mixed with a 1.8-fold molar excess of HSJ1b. On the contrary, there was no evident additive effect of this mixture when examined in the presence of Mg-ATP. Mg-ATP induced an additive effect of a 2.5-fold molar excess of Hsp90 + 3.6-fold molar excess of HSJ1b, a mixture which produced no additive effect in the presence of magnesium alone (Fig. 4B).

\section{Discussion}

Our results provide a direct evidence of the physical interaction of the eukaryotic DnaJ homologue, HSJ1b and Hsp90. HSJ1b changed the ratio of the Hsp90-associated Ca-ATPase 

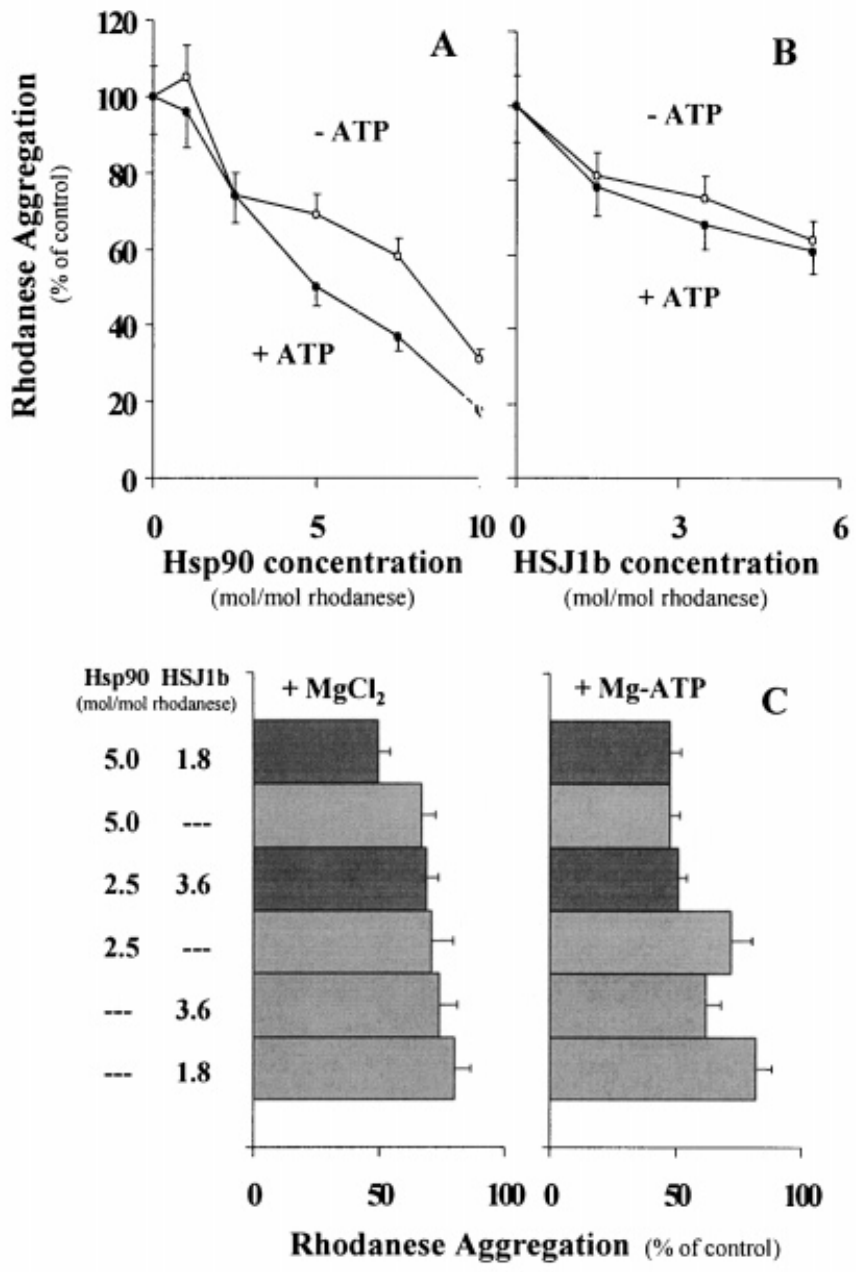

Fig. 4. Additive effect of Hsp90 and HSJ1b in preventing the aggregation of denatured rhodanese. Panels A and $\mathrm{B}$ : Attenuation of rhodanese aggregation as a function of chaperone concentration. Rhodanese $(4.6 \mu \mathrm{M})$ has been 100-fold diluted to the reaction buffer with Hsp90 (Panel A) or HSJ1b (Panel B) in molar ratios as indicated. Aggregation was measured in the presence of $2 \mathrm{mM} \mathrm{MgCl}$ (open circles) or $3 \mathrm{mM} \mathrm{MgCl}_{2}+1 \mathrm{mM}$ ATP (filled circles). Data are means \pm SD-s of 3 experiments. Panel C: Additive effect of Hsp90 and HSJ1b in preventing rhodanese aggregation. Rhodanese was diluted to the reaction buffer with, or without Hsp90 and/or HSJ1b in molar ratios indicated. Measurements were performed in the presence of $2 \mathrm{mM} \mathrm{MgCl}$ or $3 \mathrm{mM} \mathrm{MgCl} 2+1 \mathrm{mM}$ ATP as indicated. Bars represent means \pm SD-s of minimum 3 experiments.

activity and autophosphorylation in favor to the latter, which gives a further evidence for the physical interaction of the two proteins In agreement with our results, a weak interaction of Hsc70 and Hsp90 was demonstrated earlier (26,27).

An interesting finding of the present report is the ATP-dependent changes in the binding 
affinity of both HSJ1b and Hsp90 towards the partially renatured apo-lactalbumin. HSJ1b harbors three Walker-type B sequences (amino acids 21-33, 44-54 and 201-210; ref. 16) and a distorted Walker-A sequence (AGSGGPGFTFTFRSPEEV, amino acids 85-102; ref. 16) lacking the essential lysine from the GKT segment. The majority of these motifs (22$33,44-54$ and 85-102) are in the $\mathrm{J}$ and G/F domains of HSJ1b that are conserved with DnaJ. In the literature there are various reports describing no effect of ATP on the chaperone function of DnaJ (28), or a tighter binding of rhodanese to DnaJ in the presence of ATP (21). However, ATP-induced differences in binding of rhodanese to DnaJ were not observed with the N-terminal peptide of rhodanese (29), but a slight ATP-induced increase of the chaperone activity of the DnaJ homologue Hsp40 towards luciferase has also been reported (30). Our results, which show a looser binding of apo-lactalbumin to HSJ1b in the presence of ATP and essentially no ATP-induced change in the chaperone activity of HSJ1b towards rhodanese provide further details in the potential ATP-dependent actions of some DnaJ-like proteins.

In our earlier reports Hsp90 has been shown to be an ATP-binding protein (15) which changes its conformation after ATP addition (31). These findings were supported by the identification of the ATP-binding site in the N-terminal domain of Hsp90 (32) and by direct functional assays showing the involvement of ATP in the in vitro and in vivo chaperone function of Hsp90 (33-36). ATP induced a marked change in binding of the co-chaperone p23 to Hsp90 (36). However, the ATP-dependent chaperone effects of Hsp90 alone were most pronounced when only the $\mathrm{N}$-terminal domain was present, and the chaperone activity of fulllength Hsp90 showed only marginal changes in the presence of ATP (33) similarly to our findings (see Fig. 3A).

Magnesium reduces the binding affinity of apo-lactalbumin to Hsp90 compared to the control values in agreement with earlier observations on the divalent cation-induced inactivation of the Hsp90-chaperone (5). The $\mathrm{Mg}^{2+}$-induced change is reversed, when $\mathrm{Mg}$-ATP is added to the system. On the contrary, HSJ1b shows maximal binding of apo-lactalbumin in the presence of magnesium, which is reduced to the control level by the addition of Mg-ATP. The observation of the opposite changes in the apo-lactalbumin binding affinities of Hsp90 and HSJ1b led us to examine if apo-lactalbumin can be transferred from Hsp90 to HSJ1b.

Probably the most interesting finding of the present report is the ATP-dependent apparent "cooperation" of HSJ1b and Hsp90 in "presenting" apo-lactalbumin to each other (Fig. 3C). Since we did not observe a synergistic effect of HSJ1b and Hsp90 chaperone activities, we do not have a plausible model to illustrate, or explain the phenomenon observed. However, the ATP-dependent cooperation of the two proteins may be restricted to certain type of substrates. In surface plasmon resonance experiment local Hsp90 concentration is rather high (up to $1 \mathrm{mM}$ ), as well as some active sites of immobilized Hsp90, or HSJ1b are probably occupied. These specialties of SPR measurements may also contribute to the different behavior. Substrate shuttling between chaperone systems has already been demonstrated between the DnaK and GroEL chaperone machinery (23). The cooperation of the nerve-cell specific HSJ1b and Hsp90 may be another example for an element of the lateral network of chaperones. 


\section{Acknowledgments}

This work was supported by research grants from CREST, Japan Science and Technology Corporation, fellowship of the Tokyo Metropolitan Institute of Medical Science, Wellcome Trust (048222), ICGEB, OTKA-T25206, Hungarian Ministry of Social Welfare (ETT-493/ 96), and the Volkswagen Foundation (I/73612). P.C. is a recipient of an International Research Scholar's Award (HHMI 75195-541701) of the Howard Hughes Medical Institute.

\section{References}

1. W.B. PRATT and D.O. TOFT, Endocrine Rev. 18 306-360 (1997).

2. P. CSERMELY, T. SCHNAIDER, Cs. SŐTI, Z. PROHÁSZKA and G. NARDAI, Pharmacol. Therapeutics 79 129-168 (1998).

3. J. BUCHNER, Trends Biochem. Sci. 24 136-141 (1999).

4. U. JAKOB, H. LILIE, I. MEYER and J. BUCHNER, J. Biol. Chem. $2707288-7294$ (1995).

5. U. JAKOB, I. MEYER, H. BÜGL, S. ANDRE, C.A. BARDWELL and J. BUCHNER, J. Biol. Chem. 270 14412-14419 (1995).

6. B.C. FREEMAN and R.I. MORIMOTO, EMBO J. 15 2969-2979 (1996).

7. D.M. CYR, T. LANGER and M.G. DOUGLAS, Trends in Biochem. Sci. 19 176-181 (1994).

8. M.E. CHEETHAM and A.J. CAPLAN, Cell Stress \& Chaperones 3 28-36 (1998).

9. W.J. KELLEY, Trends Biochem. Sci. 23 222-227 (1998).

10. Y. KIMURA, I. YAHARA and S. LINDQUIST, Science 268 1362-1365 (1995).

11. A.J. CAPLAN, E. LANGLEY, E.M. WILSON and J.J. VIDAL, J. Biol. Chem. 270 5251-5257 (1995).

12. R.J. SCHUMACHER, W.J. HANSEN, B.C. FREEMAN, E. ALNEMRI, G. LITWACK and D.O. TOFT, Biochemistry 35 14889-14898 (1996).

13. K.D. DITTMAR, M. BANACH, M.G. GALIGNIANA and W.B. PRATT, J. Biol. Chem. 273 7358-7366 (1998).

14. S. KOYASU, E. NISHIDA, T. KADOWAKI, F. MATSUZAKI, K. IIDA, F. HARADA, KASUGA, H. SAKAI and I. YAHARA, Proc. Natl. Acad. Sci. USA 83 8054-8058 (1986).

15. P. CSERMELY and C.R. KAHN, J. Biol. Chem. 266 4943-4950 (1991).

16. M.E. CHEETHAM, J-P. BRION and B.H. ANDERTON, Biochem. J. 284 469-476 (1992).

17. M.E. CHEETHAM, A.P. JACKSON and B.H. ANDERTON, Eur. J. Biochem. 226 99-107 (1994).

18. M. BRADFORD, Anal. Biochem. 72 248-254 (1976).

19. P. CSERMELY, Y. MIYATA, Cs. SŐTI and I. YAHARA, Life Sci. 61 411-418 (1997).

20. T. SCHNAIDER, J. OIKARINEN, H. ISHIWATARI-HAYASAKA, I. YAHARA and P. CSERMELY, Life Sci. 65, 2417-2426 (1999).

21. G. NARDAI, T. SCHNAIDER, Cs. SÓTI, M.T. RYAN, P.B. HOJ, J. SOMOGYI and P. CSERMELY, J. Biosci. 21 79-190 (1996).

22. W-C. SUH, C.Z. LU and C.A. GROSS, J. Biol. Chem. 274 30534-30539 (1999).

23. T. LANGER, C. LU, H. ECHOLS, J. FLANAGAN, M.K. HAYER and F.U. HARTL, Nature 356 683-689 (1992).

24. A. OKAZAKI, T. IKURA, K. NIKAIDO and K. KUWAJIMA, Nature Struct. Biol. 1 439-446 (1994).

25. D.M. CYR and M.G. DOUGLAS, J. Biol. Chem. 269 9798-9804 (1994).

26. M.J. CZAR, J.K. OWENS-GRILLO, K. DITTMAR, K.A. HUTCHISON, A.M. ZACHAREK, K.L. LEACH, M.J. DEIBEL Jr., and W.J. PRATT, J. Biol. Chem. 269 11155-11161 (1994).

27. P.M. OUIMET and M. KAPOOR, Biochem. Cell Biol. 76 97-106 (1998).

28. A. WAWRZYNOW and M. ZYLICZ, J. Biol. Chem. 270 19300-19306 (1995).

29. W. KUDLICKI, O.W. ODOM, G. KRAMER and B. HARDESTY, J. Biol. Chem. 271 31160-31165 (1996). 
30. Y. MINAMI, J. HÖHFELD, K. OHTSUKA and F.U. HARTL, J. Biol. Chem. 271 19617-19624 (1996).

31. P. CSERMELY, J. KAJTÁR, M. HOLLÓSI, G. JALSOVSZKY, S. HOLLY, C.R. KAHN, P. GERGELY, C.S. SŐTI, K. MIHÁLY and J. SOMOGYI, J. Biol. Chem. 268 1901-1907 (1993).

32. C. PRODROMOU, S.M. ROE, R. O'BRIEN, J.E. LADBURY, P.W. PIPER and L.H. PEARL, Cell 90 65-75 (1997).

33. T. SCHEIBEL, T. WEIKL and J. BUCHNER, Proc. Natl. Acad. Sci. USA 95 1495-1499 (1998).

34. B. PANARETOU, C. PRODROMOU, S.M. ROE, R. O'BRIEN, J.E. LADBURY, P.W. PIPER and L.H. PEARL, EMBO J. 17 4829-4836 (1998).

35. W.M.J. OBERMANN, H. SONDERMANN, A.A. RUSSO, N.P. PAVLETICH and F.U. HARTL, J. Cell Biol. 143 901-910 (1998).

36. W. SULLIVAN, B. STENSGARD, G. CAUCUTT, B. BARTHA, N. MCMAHON, E.S. ALNEMRI, G. LITWACK and D. TOFT, J. Biol. Chem. 272 8007-8012 (1997). 